\title{
Inclusão digital nas escolas do campo
}

\author{
Digital inclusion in field schools \\ Inclusión digital en escuelas de campo
}

Recebido: 08/04/2021 | Revisado: 14/04/2021 | Aceito: 28/04/2021 | Publicado: 30/04/2021

\author{
Alexandra Buzanelo Schossler \\ ORCID: https://orcid.org/0000-0001-9133-3684 \\ Universidade Federal de Santa Maria, Brasil \\ E-mail: alexandraschossler@gmail.com \\ Liziany Müller Medeiros \\ ORCID: https://orcid.org/0000-0001-7325-6611 \\ Universidade Federal de Santa Maria, Brasil \\ E-mail: lizianym@hotmail.com \\ Juliane Paprosqui \\ ORCID: https://orcid.org/0000-0002-3034-2453 \\ Universidade Federal de Santa Maria, Brasil \\ E-mail: juliane_paprosqui@hotmail.com \\ Alessandra Regina Müller Germani \\ ORCID: https://orcid.org/0000-0001-7022-8543 \\ Universidade Federal da Fronteira Sul, Brasil \\ E-mail: alessandragermani@hotmail.com \\ Ivanio Folmer \\ ORCID: https://orcid.org/0000-0002-7433-6434 \\ Universidade Federal de Santa Maria, Brasil \\ E-mail: ivaniofolmer@yahoo.com.br
}

\begin{abstract}
Resumo
$\mathrm{O}$ artigo que se apresenta busca entender como são utilizados os laboratórios de informática e o uso das Tecnologias da Informação e Comunicação (TICs) nas escolas do campo da $17^{\text {a }}$ Coordenadoria Regional de Educação do Estado do Rio Grande do sul. Sendo assim, tem como objetivo geral analisar como as TICs por meio dos Laboratórios de Informática Educativa (LIES) estão sendo utilizadas como ferramentas de apoio pedagógico nas escolas do Campo. Foram pesquisadas dezesseis escolas do campo, para o desenvolvimento da pesquisa buscou-se como aporte metodológico o estudo de caso, tendo como instrumento de coleta de dados questionários aplicados a todos envolvidos no processo, quais sejam: equipe diretiva das escolas, educadores e educandos, além de pesquisa bibliográfica que buscou entender como se consolidou o programa nacional de tecnologia educacional lançado pelo governo federal em 1997, no que diz respeito a implantação de laboratórios de informática nas escolas. Os resultados encontrados apontam para ainda se faz necessário formação para os educadores para implementar em suas práticas pedagógicas a utilização dos recursos disponíveis nos LIES e também a necessidade de manutenção dos equipamentos fornecidos pelo governo.
\end{abstract}

Palavras-chave: Laboratório de informática; Educação do campo; TICs; Políticas educacionais.

\begin{abstract}
The present article seeks to understand how computer labs are used and the use of Information and Communication Technologies (TICs) in schools in the countryside of the 17th Regional Education Coordination of the State of Rio Grande do sul. Therefore, its general objective is to analyze how ICTs through the Educational Informatics Laboratories (LIES) are being used as pedagogical support tools in schools in the countryside. Sixteen rural schools were researched. For the development of the research, the case study was sought as a methodological contribution, using questionnaires applied to everyone involved in the process as the data collection instrument, namely: school management team, educators and students, in addition to bibliographic research that sought to understand how the national educational technology program launched by the federal government in 1997 was consolidated, with regard to the implementation of computer labs in schools. The results found point out that there is still a need for training for educators to implement in their pedagogical practices the use of the resources available in the LIES and also the need to maintain the equipment provided by the government.
\end{abstract}

Keywords: Computer lab; Rural education, TICs; Educational policies.

\section{Resumen}

El presente artículo busca comprender cómo se utilizan los laboratorios de computación y el uso de las Tecnologías de la Información y la Comunicación (TIC) en las escuelas del interior de la XVII Coordinación Regional de Educación del Estado de Rio Grande do sul. Por tanto, su objetivo general es analizar cómo las TIC a través de los Laboratorios 
de Informática Educativa (LIES) se están utilizando como herramientas de apoyo pedagógico en las escuelas del campo. Se investigaron 16 escuelas rurales. Para el desarrollo de la investigación se buscó el estudio de caso como aporte metodológico, utilizando como instrumento de recolección de datos cuestionarios aplicados a todos los involucrados en el proceso, a saber: equipo de gestión escolar, educadores y estudiantes, además a la investigación bibliográfica que buscaba comprender cómo se consolidó el programa nacional de tecnología educativa lanzado por el gobierno federal en 1997, en lo que respecta a la implementación de laboratorios de computación en las escuelas. Los resultados encontrados señalan que aún existe la necesidad de capacitar a los educadores para implementar en sus prácticas pedagógicas el uso de los recursos disponibles en las LIES y también la necesidad de mantener los equipos provistos por el gobierno.

Palabras clave: Laboratorio de computación; Educación rural; TIC; Políticas educativas.

\section{Introdução}

O ensino mediado pelas Tecnologias da Informação e Comunicação (TICs) pode promover mudanças nos papéis de todos os envolvidos no processo educacional, promovendo mudanças de representações e formando pessoas, não apenas para os saberes escolares, mas na formação de cidadãos mais críticos no processo de formação de uma sociedade mais igualitária (Coutinho \& Lisbôa, 2011).

No intuito de aprimorar e dar significado a aprendizagem dos educandos, assim como possibilitar às escolas públicas acompanhar o desenvolvimento tecnológico, o governo federal iniciou em 1997 o Programa Nacional de Tecnologia Educacional - PROINFO, que dentre os objetivos estava a montagem, nas escolas estaduais e municipais de Laboratórios de Informática Educativa - LIEs (MEC, 2013). Em média, no projeto inicial, estes LIEs contavam, em 2009/2010, com 18 computadores, impressoras e ar-condicionado (MEC, 2013).

Com a institucionalização dos LIEs e do Programa Integrado, principalmente na zona rural, criam-se possibilidades de aprimorar e contribuir com a promoção das práticas pedagógicas nos laboratórios de informática (MEC, 2013). A recepção da inclusão digital pelos profissionais da educação é positiva, tendo em vista que as tecnologias estão a serviço do processo educacional, sendo parte do contexto na construção do conhecimento, fazendo com que haja a mediação entre indivíduo e conhecimento, através de um instrumento tecnológico (MEC, 2013).

Neste contexto levanta-se a questão: Como estão sendo utilizados os laboratórios de informática e o uso das TICs nas escolas do campo? A fim de responder esse questionamento, empregamos como metodologia a pesquisa quali-quantitativa, de caráter exploratório, a partir de um estudo de caso, buscando fazer um diagnóstico de como as dezesseis escolas do campo da $17^{\text {a }}$ Coordenadoria Regional de Educação (CRE) do estado do Rio Grande do Sul relacionam-se com as tecnologias da comunicação e informação no processo de ensino aprendizagem de seus educandos, levando em consideração a posição geográfica das mesmas, que se distanciam dos centros urbanos.

A partir da questão levantada frente às escolas do campo da $17^{\mathrm{a}} \mathrm{CRE}$, apresenta-se como objetivo geral da pesquisa: Analisar como as TICs por meio dos LIEs estão sendo utilizadas como ferramentas de apoio pedagógico nas escolas da Educação do Campo.

\subsection{Tecnologia e Sociedade}

É incontestável que na atualidade, a tecnologia está cada vez mais presente, tanto na área do trabalho, onde as máquinas estão substituindo trabalhadores ou exigindo que estes se especializem para continuar trabalhando, quanto na área social e mesmo de lazer, onde grande parte das pessoas busca contatar com outras, através das tecnologias (Castells, 2000).

Há muito tempo, os investimentos e as inovações tecnológicas são resultados da necessidade constante do ser humano em potencializar as suas capacidades e melhorar a sua condição de vida, proporcionando mais conforto, mais recursos, eficácia, eficiência, otimização do tempo, desenvolvimento, etc (Castells, 2000). 
É consenso que o computador e a Internet transformaram a geografia mundial, ao aproximar territórios e pessoas, quebrando barreiras: "as barreiras ao conhecimento", "da participação" e "da oportunidade econômica" (ONU, 2001). São responsáveis também por alterar a cultura popular, ao modificar o relacionamento entre mercados, indústrias e consumidores, e entre governos e cidadãos. Inverte-se o papel de passivos e com pouca voz, consumidores e cidadãos deixaram de ser os últimos na hierarquia de decisão para passarem a fazer parte do processo de construção (ONU, 2001). Contudo, este poder de participação e envolvimento, definitivamente essencial na sociedade democrática, exige dos indivíduos não só competências e conhecimentos sobre as TIC e suas potencialidades, como também consciencialização sobre aquilo que Paulo Freire chama de capacidade da ação humana (Freire; Macedo, 1990).

Desta forma, faz-se necessário que a escola prepare os seus educandos para utilizar as TICs e poder tirar o máximo proveito das suas potencialidades. Porém, se num primeiro momento, a introdução de uma educação midiática parece resolver o problema, uma análise mais aprofundada sobre o tema levanta questões pertinentes sobre o ambiente escolar, os currículos, a formação dos educadores, a relação educador/educando.

Para que as TICs possam trazer alterações no processo educativo, no entanto, elas precisam ser compreendidas e incorporadas pedagogicamente. É preciso respeitar as especificidades do ensino e da própria tecnologia para poder garantir que o seu uso, realmente, faça a diferença. Não basta usar a televisão ou o computador, é preciso saber a forma de usar pedagogicamente correta a tecnologia escolhida (Kenski, 2007, p. 46).

Neste contexto, é importante que o espaço escolar se aproprie dos mais variados meios de comunicação para buscar a construção do conhecimento que venha a somar para a vida do educando em todos os aspectos. Diante disso:

[...] os diferenciados meios comunicacionais possibilitam que a aprendizagem ocorra em múltiplos espaços, seja nos limites físicos das salas de aula e dos espaços escolares formais, seja nos espaços virtuais de aprendizagem (Kenski, 2008, p. 652).

Para que haja essa apropriação, é necessário principalmente que a escola esteja preparada com uma estrutura para essas mudanças, educadores com formação continuada para trabalhar as TICs é fundamental, porém se não houver uma internet de qualidade, um laboratório de informática que atenda às necessidades básicas dos educandos, essa apropriação não será possível. Na busca de sanar essas necessidades, uma parceria entre governos Federais, Estaduais e Municipais, cria em 1997 o Programa Nacional de Informática na Educação - PROINFO, que busca equipar as escolas com Laboratório de informática.

A proposta inicial do PROINFO era capacitar 25 mil professores e atender a 6,5 milhões de estudantes do ensino fundamental e médio, das redes estaduais e municipais, por meio da aquisição de 100 mil computadores instalados e interligados à Internet (Schnell, 2009). Um dos objetivos do programa era a formação continuada de professores. Nesse sentido, foram criados os Núcleos de Tecnologia Educacional (NTE), constituídos por várias equipes de educadores e por especialistas em informática e telecomunicações, estruturados para a formação em tecnologias da informação e comunicação (BRASIL, 2007).

A partir de 2007, buscando acelerar o processo da inclusão digital, a Presidência da República, por meio do Decreto $\mathrm{n}^{\circ}$ 6.300, de 12 de dezembro de 2007, elaborou novas diretrizes para o PROINFO (BRASIL, 2007), dentre os objetivos estão: I - promover o uso pedagógico das tecnologias de informação e comunicação nas escolas de educação básica das redes públicas de ensino urbanas e rurais; II - fomentar a melhoria do processo de ensino e aprendizagem com o uso das tecnologias de informação e comunicação; III - promover a capacitação dos agentes educacionais envolvidos nas ações do Programa; IV - 
contribuir com a inclusão digital por meio da ampliação do acesso a computadores, da conexão à rede mundial de computadores e de outras tecnologias digitais, beneficiando a comunidade escolar e a população próxima às escolas.

\subsection{Tecnologia, educação e sujeitos do campo}

A partir da implementação dos LIEs, através do PROINFO, nas Escolas do Campo, foi possível aos educadores construir práticas pedagógicas inovadoras. Dessa forma, é importante que ocorra uma análise dessas práticas e dos LIEs. Introduzir as tecnologias nas práticas pedagógicas implica em mudanças e envolvimento, tanto técnicas como na formação dos educadores e demais indivíduos que atuam na escola no intuito de prepará-los para uso do computador como instrumento de auxilio à construção do conhecimento, e ao educando, na aprendizagem (Oliveira, 2009).

As crianças e jovens, quando chegam às escolas do campo, trazem na bagagem experiências de vida extremas, descritas em suas falas, linguagem e culturas (Arroyo, 2013), fazendo com que os educadores necessitem adaptar a escola para esses indivíduos. Conforme Souza (2006), as escolas do campo precisam ser pensadas a partir das culturas já existentes, preservando os saberes do campo e vivenciando o cotidiano da vida no campo.

A educação do campo é um espaço propício para reflexões sobre interdisciplinaridade, uma vez que o próprio campo caracteriza-se por uma diversidade cultural, social e econômica. Dar continuidade à educação do campo requer a análise das especificidades de cada lugar. O campo é o lugar da pequena produção, do sem terra, do posseiro, do indígena, do quilombola, dos atingidos por barragens, dos arrendatários, meeiros, posseiros, boias frias. Cada uma das atividades gera experiências e práticas social diversificada, cuja identidade pode ser construída no espaço comunicativo do movimento social e na gestão coletiva de vida na escola (Souza, 2006, p.24).

Com o uso das TICs, educadores e educandos descrevem suas ideias, trocam experiências, produzem histórias e desenvolvem projetos que podem ser usados no dia-a-dia da escola. Possibilita que os educandos se integrem com a comunidade que os cercam e a outros espaços produtores de conhecimento conforme:

A Cultura fornece um enorme equipamento cognitivo aos indivíduos. A cada etapa da nossa trajetória social, a coletividade nos fornece línguas, sistemas de classificação, conceitos, analogias, metáforas, imagens, evitando que tenhamos que inventá-las por conta própria (Levy, 1998, p. 142-143).

Dessa forma, a escola tem o dever de oportunizar aos educandos desenvolverem habilidades, levando em conta o conhecimento que já possuem, aperfeiçoando com os conhecimentos dos educadores, os quais deverão utilizar das tecnologias fornecidas pela escola para a mediação do conhecimento. A escola do campo é rica em costumes e valores, assim se torna de suma importância a sua preservação e o seu resgate a fim de contribuir com o desenvolvimento dos cidadãos que a compõem. (Bierhalz; Fonseca \& Oliva, p.8 2019)

Neste sentido, é de suma importância o uso das tecnologias como ferramenta de mediação pedagógica para a promoção de uma educação de qualidade, mas é importante que o educador receba orientações para assumir o papel de mediador nesse processo de apropriação das novas tecnologias.

\section{Metodologia}

Esse trabalho desenvolve-se a partir de duas abordagens. Qualitativa, quando realizada uma leitura de como os LIEs estão sendo utilizados nas escolas, a partir dos questionários que são, em parte, descritivos. Ocorre uma segunda abordagem, essa de ordem quantitativa, quando da leitura dos números e parte dos questionários que são objetivos. Quanto aos objetivos dessa pesquisa são de caráter exploratório, pois envolve levantamento bibliográfico, entrevistas em forma de questionários com pessoas que têm ligação direta com o tema pesquisado, sendo realizada a análise desses dados. No que diz respeito aos 
procedimentos técnicos, essa pesquisa pode ser classificada como Estudo de Caso, pois envolve um estudo profundo, com amplo e detalhado conhecimento (GIL, 2008). Foram visitadas 16 (Dezesseis) escolas que perfazem a $17^{\mathrm{a}}$ Coordenadoria Regional de Educação, nas quais foram aplicados questionários, tanto para a equipe diretiva quanto para os educadores e educandos que versavam sobre a utilização das tecnologias da informação e comunicação na escola, buscando com isso fazer um diagnóstico da utilização dos laboratórios de informática nas respectivas escolas no contexto da educação do campo.

\section{Resultados e Discussão}

\section{Equipe diretiva:}

As escolas que participaram deste estudo de caso iniciaram seus trabalhos entre os anos de 1924 até 1969, somente uma escola que por um período foi considerada urbana, as demais sempre foram rurais e, com as mudanças na constituição, passaram a denominar-se do campo.

Quanto ao calendário escolar, todas as escolas seguem o calendário proposto pela Secretaria de Educação de seu município, pois seus educandos necessitam de transporte escolar para se deslocarem. Somente uma escola apontou trabalhos diferenciados para os educandos no período da colheita, seguindo o que prevê a Lei no 9.394/96, LDB, que no Artigo 23, §2, define que o calendário escolar deverá adequar-se às peculiaridades locais, inclusive climáticas e econômicas, a critério do respectivo sistema de ensino, sem com isso reduzir o número de horas letivas previstas na lei. Quanto à filosofia das escolas do campo, somente uma escola propõe a valorização do lugar onde vive.

Grande parte das escolas estimula o uso das tecnologias e do laboratório de informática, mesmo enfrentando muitas dificuldades, principalmente no que diz respeito aos computadores muito antigos. Seguem dois relatos relevantes e que mostram a dicotomia entre duas escolas em relação ao uso das tecnologias:

"Todas as disciplinas utilizam a pesquisa no laboratório de informática, que conta com 18 computadores, internet, lousa digital, aparelho de TV" (Escola 02).

"Infelizmente, temos computadores muito velhos, que estragam constantemente. No ano passado, aumentamos as gigas da internet, mas ainda é lenta e todos professores fazem uso quase que diariamente” (Escola 04).

Alguns fatores implicam nas dificuldades do uso desses laboratórios:

Levar a tecnologia para sala de aula como objetivo de estar a serviço de uma aprendizagem significativa ainda é um desafio numa realidade educacional pública carente de recursos básicos, como dinheiro para a compra de merenda escolar, bem como infraestrutura básica. A questão de como implementar uma política de TIC a serviço da melhoria do processo educacional é enfatizada por diferentes autores, lançando um importante alerta de que não basta implementar uma infraestrutura para alcançar consequências positivas no processo de ensino e aprendizagem. (Bielshowsky, 2009, p. 9).

Nenhuma escola possui rádio, blog, Facebook. Desta forma, a partir do que foi relatado pelas equipes diretivas das Escolas do Campo, percebe-se que se faz necessário estimular o uso das TICs. Também criar mecanismos que façam com que as escolas estruturem os LIEs para atender à demanda tanto dos educadores como dos educandos.

\section{Equipe Educadores:}

Reconhecer o perfil do profissional que trabalha com a Educação do Campo é muito importante para compreender o processo de construção do conhecimento nas Escolas do Campo. Deve-se levar em consideração que esses profissionais têm 
um grande desafio, tanto no que diz respeito a trabalhar a Educação do Campo, como também de associar as TICs a esse processo.

As escolas do campo da $17^{\mathrm{a}} \mathrm{CRE}$ possuem $90 \%$ dos educadores do sexo feminino e $10 \%$ do sexo masculino. Outro dado de grande importância é que a maioria dos educadores que trabalha nas Escolas do Campo tem mais de 40 anos, o que pode ser justificado pela hierarquia interna do Governo Estadual, onde os professores mais antigos podem escolher primeiro onde querem trabalhar.

Em se tratando do regime de trabalho dos educadores das Escolas do Campo 24\% deles trabalham menos de 20 horas, chegando a 4 horas semanais em algumas escolas, 62\% desses, tem um regime de 20 horas de trabalho semanal nas escolas, apenas $14 \%$ trabalham 40 horas semanais. Em relação à residência dos educadores, $77 \%$ responderam que moram na zona urbana, enquanto $23 \%$ moram na zona rural e, destes, $26 \%$ têm suas residências perto das escolas.

Quanto à formação desses educadores, apenas 3\% têm formação inicial, magistério, sem outra formação superior; 97\% têm ensino superior, 45\% dos professores têm especialização e nenhum possui mestrado ou doutorado.

Neste sentido aponta-se a fragilidade na formação desses educadores em relação à Educação do Campo, tendo em vista que nenhum apresenta formação inicial, nem mesmo especialização voltada ao tema. Necessidade essa enfatizada:

As necessidades presentes na escola do campo exigem um profissional com uma formação mais ampliada, mais totalizante, já que ele tem de dar conta de uma série de dimensões educativas presentes nessa realidade (Rocha, 2009, pag. 41).

Cerca de $90 \%$ dos educadores têm acesso à internet todos os dias da semana, os outros 10\%, têm uma frequência menor, entre cinco e seis vezes na semana quanto ao local de acesso à internet, $62 \%$ dos educadores informaram utilizá-la em casa e no local de trabalho, 35\% dos educadores só acessam à internet em casa, e 4\% dos educadores só têm acesso no local de trabalho.

Desta forma, os resultados indicam que a maioria dos educadores tem acesso à internet, podendo utilizar essas ferramentas para potencializar os planejamentos das aulas. Possibilitando recursos didáticos, fontes bibliográficas e variedade de informações, promovendo a construção do conhecimento a partir de redes colaborativas de conhecimento científico, exercendo um papel fundamental na constituição do sujeito do campo.

Ao serem questionados sobre os aplicativos básicos os quais sabem usar o editor de textos foi o mais indicado pelos educadores, com 95\%. Já o editor de vídeo foi o aplicativo que os educadores apontaram como com menos conhecimento.

Nas escolas do campo, 98\% dos educadores utilizam internet para realizar pesquisas para o planejamento e elaboração de suas aulas. Nesse sentido, os sites mais utilizados são aqueles de caráter educativo ( $31 \%$ dos educadores), seguido do Google (21\% dos educadores). Quanto aos trabalhos desenvolvidos no laboratório de informática $67 \%$ dos educadores levam os educandos para atividades de pesquisa e complemento das atividades em sala de aula, enquanto que $33 \%$ dos educadores, disseram não realizar qualquer atividade nos laboratórios.

Apenas 19\% dos educadores das Escolas do Campo utilizam softwares educativos e objetos de aprendizagem no laboratório de informática. Esse dado leva a questão de que falta conhecimento tecnológico por parte dos educadores para o processo de ensino e aprendizagem.

Quanto aos recursos utilizados no processo de ensino e aprendizagem, destacam-se os livros, o quadro branco e canetas para quadro, seguidos do datashow e de jornais e revistas. O computador foi indicado por $56 \%$ dos educadores e a internet por 54\%, apontando, mais uma vez, que, mesmo sendo usados esses recursos pela maioria dos educadores, em algumas Escolas do Campo, o uso das tecnologias ainda é pouco utilizado. 
Em relação à questão de como os educadores do campo conceituam as TICs, apontam-se alguns relatos que se destacaram dentre as respostas. A importância de se utilizar as tecnologias de forma responsável, e também dar significado a esse aprendizado, estiveram entre a maioria das respostas:

"Importante para a vida em sociedade. Facilita o aprendizado desde que saibamos usá-la e que não nos tornemos dependentes de máquinas, pois precisamos de conhecimento e não apenas informações" (Educador 01).

“Como 'faca de dois gumes', depende para que e como utilizá-la. É uma ferramenta muito importante para auxiliar no trabalho diário de todas as pessoas pela rapidez das informações e comunicações. Mas quando não usada com responsabilidade, pode causar sérios problemas" (Educador 09).

Houve relatos de educadores que veem as TICs como importantes no processo de ensino e aprendizagem, porém, as Escolas do Campo em que trabalham, apresentam alguns problemas relacionados às tecnologias:

"A tecnologia é muito escassa em nossas escolas, pois a rede elétrica não comporta e há poucos computadores nas escolas." (Educador 38).

"Considero que são meios indispensáveis no mundo em que vivemos hoje: rodeados de meios tecnológicos diversos. Porém é verdade que as dificuldades de acesso existem e são barreiras que impedem o uso das tecnologias em locais/níveis em que seria possível. Por exemplo, um laboratório de informática em uma escola, que não tem PCs para todos os alunos e pior, não tem acesso a internet". (Educador 39).

A maioria dos educadores, $69 \%$ deles, já fizeram algum curso de informática, apenas 31\% disseram não ter realizado nenhum curso. Dos educadores que responderam terem realizado cursos, $42 \%$ disseram que realizaram cursos junto ao NTE de suas Coordenadorias, os demais fizeram cursos particulares.

Mesmo estando cientes da importância do uso das TICs em sala de aula, os educadores apontaram muitas dificuldades que enfrentam todos os dias. Alguns demonstram dificuldade por motivos de falta de formação para tal:

"A falta de conhecimento de recursos que poderiam ajudar no desenvolvimento das aulas, às vezes não sabemos como utilizar a tecnologia." (Educador 07).

"Falta de conhecimento para trabalhar na internet.". (Educador 67).

Outros relatam os problemas relacionados com equipamentos muito antigos, e com o sinal da internet:

"Pouco conhecimento de como funcionam os equipamentos" (Educador 02).

"Problemas com funcionamento de computadores."; "Falta de Conexão Internet (as vezes)" (Educador 04)

Desta forma, uma análise da utilização dos LIEs nas Escolas do Campo, dá conta de que a falta de sinal de internet de qualidade, a falta de manutenção dos equipamentos, a quantidade limitada de equipamentos e a falta de formação dos educadores são as maiores dificuldades para se trabalhar com TICs na educação do campo, tendo em vista que nenhuma das escolas possui profissional responsável pelo laboratório de informática.

Entretanto, nem todas as Escolas do Campo apresentam dificuldades em relação aos laboratórios de informática, ou a 
falta de formação, conforme relatos a seguir:

"não há dificuldades, pois temos um laboratório muito bem equipado com computadores, internet, etc, e os alunos dispostos a buscar informações" (Educador 06).

As dificuldades dos educandos relatadas pelos educadores em relação aos LIEs são pequenas, apenas $14 \%$ dos educadores fizeram algum relato sobre dificuldade que os educandos têm com as atividades desenvolvidas, dentre elas, estão as escolas que não possuem internet, ou cujo laboratório de informática não está em pleno funcionamento.

Ainda, questionados sobre o envolvimento das tecnologias com as questões do campo, $63 \%$ dos educadores, disseram que buscam envolver os temas, $16 \%$ disseram que sempre que possível, e apenas $12 \%$ foram enfáticos em afirmar que não fazem relação entre as tecnologias e o espaço rural.

\section{Equipe Educandos:}

Os educandos das escolas do campo da $17^{\mathrm{a}} \mathrm{CRE}$ que responderam aos questionários apresentam idades entre 11 e 20 anos. As respostas foram $52 \%$ de educandos do sexo feminino e $48 \%$ dos educandos do sexo masculino.

Dos educandos, $92 \%$ moram na zona rural, enquanto que $8 \%$ moram na zona urbana, $79 \%$ dos educandos utilizam o transporte escolar para se deslocarem até a escola, 14\% educandos vão a pé por morarem perto e 7\% dos educandos utilizam carro próprio. Em relação à questão sobre quais os recursos que mais gostam que os educadores utilizem, o computador veio em primeiro lugar, com $69 \%$ indicações, seguido dos livros, projetores e mapas.

Quando foram questionados se utilizavam a internet para realizar trabalhos e pesquisas escolares, $88 \%$ dos educandos responderam que sim, e apenas $12 \%$ disseram que não utilizam internet para realizar os trabalhos. Os sites mais utilizados são o Google, com 168 indicações, seguido do Wikipédia, com 121 indicações, InfoEscola, com 45, Youtube com 44 e demais sites.

Quando questionados sobre a dificuldade de aprender as matérias ensinadas em sala de aula, 66\% educandos responderam que não têm dificuldades, $22 \%$ responderam ter dificuldades, sendo que a maioria alegou como motivos não prestarem atenção às aulas ou participarem de conversas paralelas que atrapalham a concentração nos estudos. Ao serem questionados sobre as atividades que mais gostam de fazer na escola, 59\% dos educandos responderam que eram atividades como jogos e as aulas de Educação Física, 7\% dos educandos apontaram que estudar e ler eram seus maiores interesses. Os demais apontaram outras atividades extraclasse como sendo de sua preferência na escola.

Sobre a questão que versa a respeito do trabalho voltado para a Educação do Campo, $51 \%$ dos educandos responderam que a atividade que mais representa o campo é o trabalho desenvolvido na horta. Também a limpeza da escola foi citada por 18\% dos educandos, depois as palestras e cursos com a Emater, que totalizaram 19\% das citações.

Quanto ao questionamento sobre continuarem estudando depois de terminado o Ensino Fundamental, 82\% dos educandos pretendem seguir estudando. Destes, $9 \%$ querem somente terminar o Ensino Médio, e os demais ainda não sabem se querem continuar estudando.

A última questão para os educandos era sobre como eles gostariam que fosse a escola para eles estudarem. Nessa questão, não teve unanimidade, tendo em vista que os sonhos são particulares de cada um. As opções que mais apareceram foram internet de qualidade com Wi-fi, uma escola maior, mais viagens e interação com outras escolas, e mais respeito entre todos dentro da escola. 


\section{Conclusão}

A pesquisa realizada apontou que a maioria dos educadores possuem formação na área das tecnologias, porém, muitos ainda sentem dificuldades em trabalhar na internet. Grande parte desses educadores sente muita dificuldade em trabalhar com softwares educativos, muitos sequer sabem o que é. Os educandos das Escolas do Campo em questão demonstraram em grande número terem acesso às tecnologias de alguma forma, assim como à internet. Os educandos das escolas onde tem laboratório de informática de qualidade, assim como, bom sinal de internet demonstraram-se satisfeitos, julgando as atividades voltadas para a tecnologia como aquelas que mais gostam de realizar na escola.

Já, os educandos onde as escolas não possuem laboratório funcionando adequadamente apontaram esse dado como sendo atividades que gostariam ter disponíveis na escola, enfatizando que para além da implantação de laboratórios se faz necessário também a manutenção destes equipamentos os quais colaboram com práticas pedagógicas mais inovadoras.

Contudo observa-se que em pesquisas futuras poderá ser investigado como se dá a implementação e manutenção dos laboratórios de informática, se existe atualização dos componentes de hardware e software bem como formação continuada para os professores para utilização destes recursos e para utilização multimidiática para além dos laboratórios.

\section{Referências}

Arroyo, Miguel G (2013b). Outros sujeitos, outras pedagogias. Vozes.

Bielschowsky, C. E. (2009). Tecnologia da Informação e Comunicação das Escolas Públicas Brasileiras: o programa PROINFO integrado. Revista e curriculum, São Paulo, 5(1), 1-35. http://portaldoprofessor.mec.gov.br/storage/materiais/0000011606.pdf

Bierhalz, C. D. K., Medeiros da Fonseca, E., \& de Vargas Oliva, I. (2019). Concepções dos estudantes de uma escola do campo sobre tecnologia. Revista Brasileira De Educação Do Campo, 4, e3297. https://doi.org/10.20873/uft.rbec.v4e3297

Brasil. (1996). Lei n. 9.394/96. Lei de Diretrizes e Bases da Educação Nacional. Ministério da Educação. Brasília. Lei de Diretrizes e Bases da Educação Nacional - LDB - de 1996. http://www.planalto.gov.br/ccivil_03/leis/19394.htm

Brasil. (2007). Decreto $n^{\circ}$ 6.300. Dispõe sobre o Programa Nacional de Tecnologia Educacional - ProInfo. Diário Oficial da República Federativa do Brasil. Brasília, DF, 13 dez. 2007. http://www.planalto.gov.br/ccivil_03/_Ato20072010/2007/Decreto/D6300.htm

Castells, Manuel. (2000). A era da informação: economia, sociedade e cultura. In: A Sociedade em rede. Paz e Terra, v.1.

Coutinho, Clara \& Lisboa, Eliana. (2011). Sociedade da Informação, do conhecimento e da aprendizagem: desafios para educação no século XXI. Revista Educação, Vol. XVIII, nº1.

Gil, A.C. (2008). Métodos e Técnicas de Pesquisa Social. Atlas. http://www.educacao.rs.gov.br/17-cre-santa-rosa

Kenski, V. M. ( 2008). Educação e tecnologias o novo ritmo da informação. $4^{\mathrm{a}}$ Ed. Papirus.

Kenski, V. M. (2007). Educação E Tecnologias. Coleção Papirus educação, Papirus Editora.

Lévy, P. (1998). A máquina universo: criação, cognição e cultura informática. Artmed.

Oliveira, B. C. M. (2009). A sala de informática em uma escola do campo: concepções e práticas da comunidade escolar. Dissertação apresentada ao Programa de Pós- Graduação - Mestrado em Educação. Universidade Católica Dom Bosco, Campo Grande/ Mato Grosso do Sul.

ONU. Programa das Nações Unidas para o Desenvolvimento. (2001). Tradução de Alexandre Abreu et al. Relatório do desenvolvimento humano 2001: novas tecnologias e desenvolvimento humano. Lisboa: Trinova.

pid=S0100-19652003000100004\&script=sci_abstract\&tlng=pt

Rocha, M. I. A. (Org). (2009). Licenciatura em Educação do Campo: Histórico e projeto político-pedagógico. Educação do Campo, desafios para a formação de professores. Autêntica Editora.

Schnell, R. F. (2009). Formação de professores para o uso das tecnologias digitais: um estudo junto aos núcleos de tecnologia educacional do Estado de Santa Catarina. 103 f. Dissertação (Mestrado em Educação) - Centro de Ciências Humanas e da Educação, Universidade do Estado de Santa Catarina, Florianópolis http://www.dominiopublico.gov.br/pesquisa/DetalheObraForm.do?select_action=\&co_obra=164307

Souza, Maria Antônia de. (2006). Educação do campo: propostas e práticas pedagógicas do MST. Vozes. 